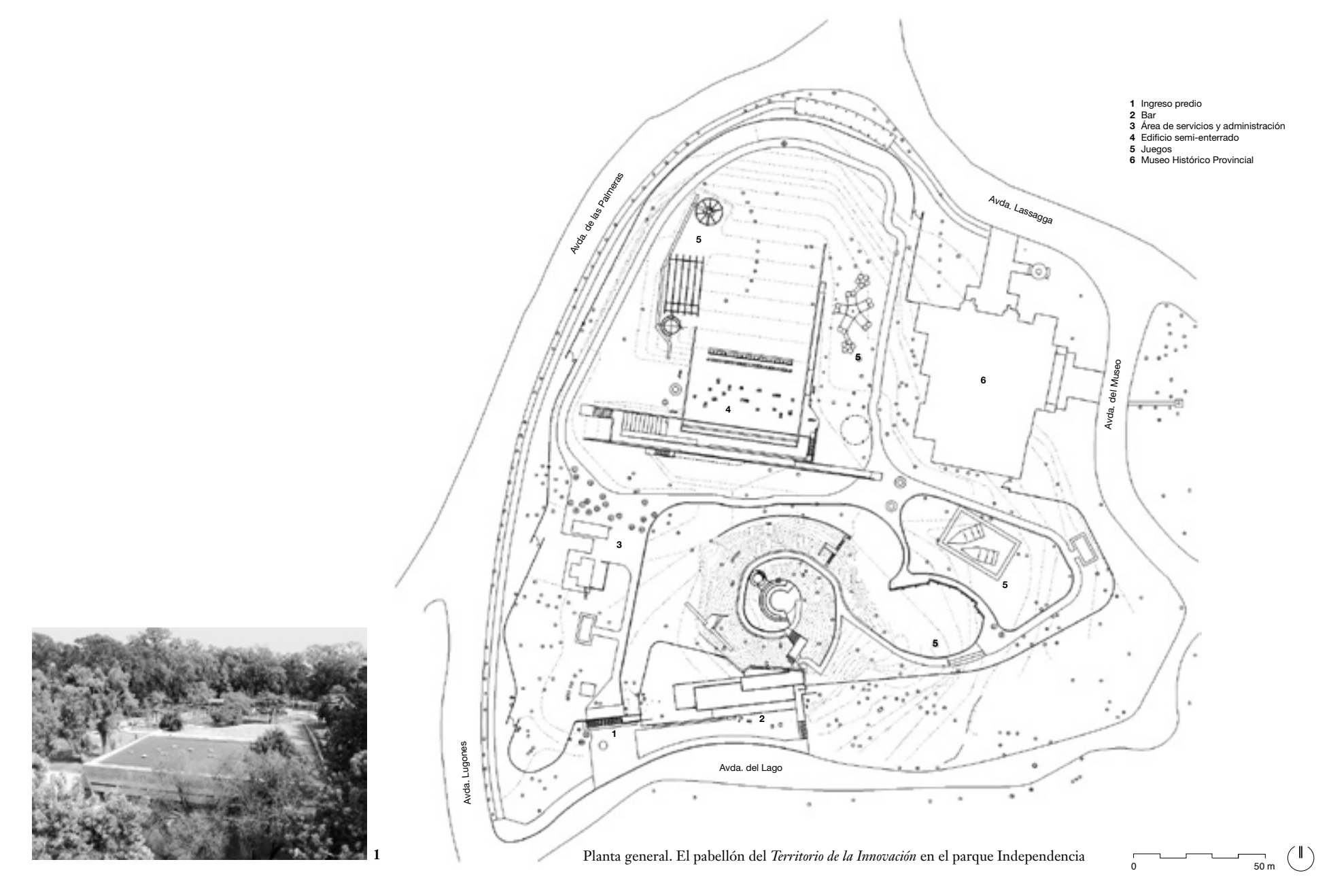

Marcelo Perazzo

Rosario, Argent

\section{Jardín de los niños}

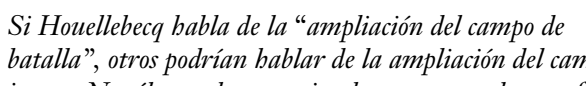

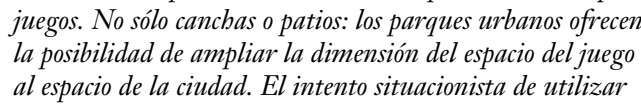

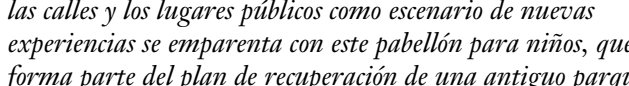

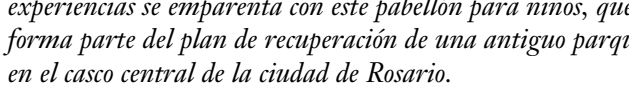

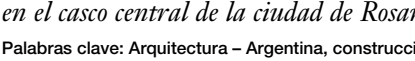

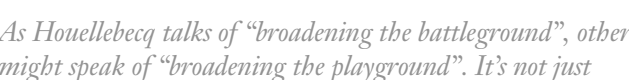

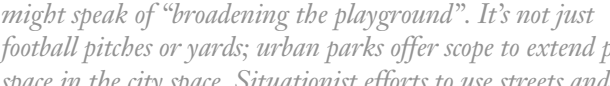

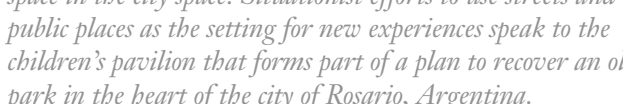
El juego de la democracia. En la relación entre incluyen relaciones diversas con los contextos es posible juzgar la

rbana intensa si de su alcance para los vecinos, y si es capaz de labor del planeamiento urbano sería la de pens generar los cambios necesarios en las condiciones passajes incompletos, capaces de cobrar sentido espacio publico abarcamos variadas categorias: El plan "Cindad de los ninos" de Rosario apun del territorio. Básicamente estamos hablando los más pequeños, en el entendido que a partir del antiguo "bien comun"; del patrimonio que de ellos es que se generan los cambios sociales heredamos y transmititremos, de las diferentes del futuro. Se trató de una empresa colectiva zonas de aprendizaje, juego y convivencia, de la $\quad$ paciente, que debió soportar muchos niveles de nuestros recorridos, y porqué no, también lo múltiple, y construimos lugares de encuentro de normas legales, servicios de accesibilidad a aprendizaje y convivencia. Lugares entre lo
Arquitectura y juego: el paisaje de la trozos de ciudad, y relaciones reguladas con el medio ambiente. Es un conjunto de escenas que

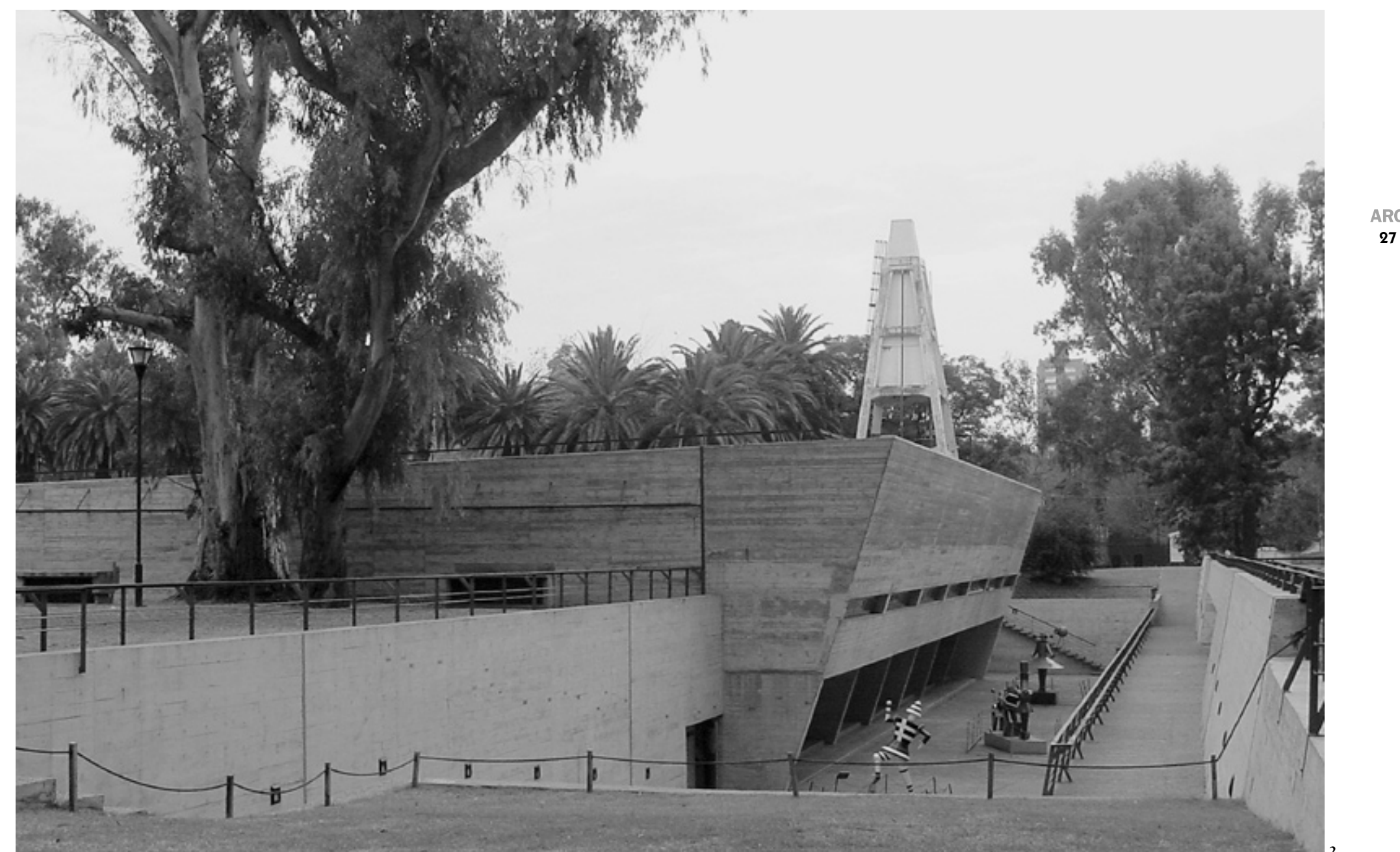

mítico y lo contemporáneo, entre lo austero y lo voluptuoso de la naturaleza, lugares integrados a na ciudad que se presenta como gran urbe, pero El jardín de niños "Juana Elena Blanco" se instala en el solar que antes ocupaba el zoológico
de la ciudad, dentro del enorme paño verde que constituye el parque Independencia, lugar historico dentro de la trama céntrica de lugar del consumir a provocar a la imaginación y redimensionar el mundo poético de los niños; un lugar abierto de juegos $\mathrm{y}$ exploraciones, organizado en tres teritorios que integran áres construcciones nuevas:

La Montañita encierra un recorrido entre ba espesa vegetación del parque, articulado con

政

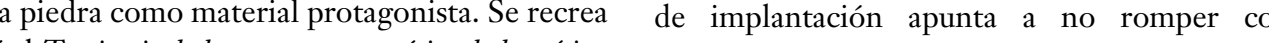

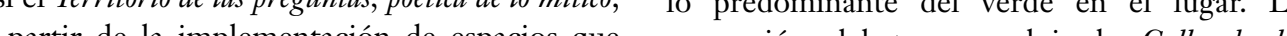
do el agua, el fuego y el sonido recrean Sicesos, luger etrerior de acontecimientos, ior del edificio con $\mathrm{s}$ tefactore De materiali abtiene por la austera, la riqueza expresiva se

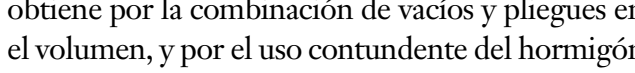
a la vista, los pisos de piedra lavada, los grandes dispuestos en un recorrido entre el prado verde y sus arboles centenarios perimetrales; constituyen al recrear las ansias de la humanidad por la Agradecimientos al arquitecto Guillermo Castiglioni, de la Dirección de Proyectos de por su colaboración en la recopilación del En el edificio semienterrado se desarroll
Territorio de la Imnovación, la poética de

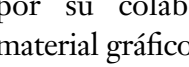


